http://jmscr.igmpublication.org/home/ ISSN (e)-2347-176x ISSN (p) 2455-0450

crossref DOI: https://dx.doi.org/10.18535/jmscr/v8i1.19

Journal Of Medical Science And Clinical Research

\title{
Comparative Study of Body Fluid Cytology Using Cytospin and Centrifuge
}

Authors

Dr Vidushi Mishra ${ }^{1}$, Dr Prapti Gupta ${ }^{2 *}$, Dr Parul Singhal ${ }^{3}$

${ }^{1}$ Junior Resident Department of Pathology Saraswathi Institute of Medical Sciences Hapur (U.P.)

${ }^{2}$ Junior Resident Department of Pathology Saraswathi Institute of Medical Sciences Hapur (U.P.)

${ }^{3}$ Professor Department of Pathology Saraswathi Institute of Medical Sciences Hapur (U.P.).

*Corresponding Author

Dr Prapti Gupta

\begin{abstract}
Objective: Comparative study of body fluid cytology using cytospin and centrifuge.

Material and Method: Our study was carried out on 100 patients admitted in wards of Saraswathi Institute of Medical Sciences Hapur (U.P.). Samples of ascitic, pleural and cerebrospinal fluids aspirated from admitted patients.The fluids was equally divided and simultaneously centrifuged in ordinary centrifuge and Cytospin. The smears for both methods were fixed for Giemsa stain. Other stains like Pap and H\&E were done only for those cases which will be positive for malignancies. Both methods were compared on the basis of Background, cell morphology, cell yield and distribution of cells.

Result: Cytospin showed better cell yield, cell morphology, cell distribution as compared to Centrifuge in pleural, peritoneal fluids and CSF but background was not comparable.

Conclusion: Cytospin was found superior to conventional centrifuge smears in terms of cell yield, preservation of cell morphology and uniformity of cell distribution. Cytospin helped in better diagnosing malignant effusions than conventional smears. Hence, cytospin can be preferred to conventional smears for cytologic examination of body cavity fluids.

Keywords: Cytospin, Centrifuge.
\end{abstract}

\section{Introduction}

Exfoliative cytology is the study of spontaneously shed cells which line an organ or a cavity, from where these cells are removed by non-abrasive means ${ }^{1}$.It comprises of study of cells from anatomic locations like effusions, CSF and synovial fluids as well as cells which are shed from urinary, respiratory and female genital tracts The cells exfoliated in the fluids and washes can be concentrated by the process of centrifugation and can be directly transferred on to the smears. This simple method of examination of cells by using light microscopy remains an important aspect till date, inspite of the tremendous progress in the development of sophisticated techniques ${ }^{2}$. Cytospin is specifically designed to concentrate cells that are found in small numbers. The technique can stretch and distort cellular and nuclear morphology and allow nucleoli to appear more prominent than would normally be seen in peripheral smears. However, it does not change nuclear: cytoplasmic ratios nor does it alter relative chromatin textures or clumping patterns ${ }^{3}$. All these features make cytospin a better diagnostic technique. This study familiarise with the efficacy and utility of various techniques in the 
study of effusion which includes conventional centrifuge and cytospin ${ }^{4}$.

\section{Aims and Objectives}

To compare the morphological features of conventional smear(centrifuge) method with those of cytospin and to assess the utility and sensitivity of cytospin and centrifuge methods in cytodiagnosis of effusion in patients attending the outpatient and inpatient services of Saraswathi institute of medical sciences, Hapur (U.P.).

\section{Material and Methods}

This was a prospective study which was carried out in the department of Pathology at Sarawathi Institute of Medical Sciences, Hapur over a period of one year and two months. In the study, a total of 100 samples of ascitic, pleural and cerebrospinal fluids aspirated from admitted patients of medical, surgical and gynaecology wards were studied. The fluids was equally divided and simultaneously centrifuged in ordinary centrifuge and Cytospin. Three parameters speed, time and acceleration rate were selected $^{5}$. The parameters once selected were held in a volatile memory. Fluids were centrifuged at $1000 \mathrm{rpm}$ for 10 minutes in Cytospin. In the centrifuge the speed and duration used was 1500 rpm and 5 minutes respectively. The smears for both methods were fixed for Giemsa stain. Other stains like Pap and H\&E were done only for those cases which were positive for malignancy After staining and mounting, the slides were examined under the microscope and compared on basis of cell yield, cell morphology, cell distribution and background $^{6}$.

\section{Results}

Table no: 1 Distribution of cases

\begin{tabular}{|l|c|c|c|}
\hline Type of fluid & Pleural & Peritoneal & CSF \\
\hline No:of Cases & 39 & 48 & 13 \\
\hline
\end{tabular}

Total No. of samples subjected to cytological examination were 100 .Out of 10039 were pleural fluids, 48 were peritoneal fluids and 13 were CSF samples

Table no:2 Age distribution

\begin{tabular}{|c|c|}
\hline Age Category & No: of Cases Observed \\
\hline $0-20$ Yrs & 18 \\
\hline $20-40$ Yrs & 27 \\
\hline$>40$ Yrs & 55 \\
\hline Total & 100 \\
\hline
\end{tabular}

Among 100 cases, 18 cases belonged to 0-20 years, 27 cases belonged to 20-40 years and 55 cases belong more than 40years.

Table no: 3 Benign/Malignant samples

\begin{tabular}{|l|c|c|c|}
\hline Type of fluid & Benign & Malignant & Total \\
\hline Pleural fluid & 38 & 1 & 39 \\
\hline Peritoneal fluid & 44 & 4 & 48 \\
\hline CSF & 13 & 0 & 13 \\
\hline Total & 95 & 5 & 100 \\
\hline
\end{tabular}

In 39 Pleural fluid samples 1 was found malignant. In 48 Peritoneal Fluid samples 4 were malignant while in CSF samples all 13 cases were benign

\section{Scoring System for Comparison of Different Parameter}

Both the conventional centrifuged smears and cytospin smears were examined. The morphological features like cell yield, cell morphology, cell distribution and background were analysed and scored, as 0, 1 and 2 as per Archana et $\mathrm{al}^{7}$.

\begin{tabular}{|l|l|c|}
\hline Parameter & Quantitative Description & Point Score \\
\hline Background blood or & 1.Large amount, great compromise in diagnosis & 0 \\
Proteinaceous material & 2.Moderate amount,diagnosis possible. & 1 \\
& 3.Minimal, diagnosis easy & 0 \\
\hline Amount of cellular & 1.Minimal to absent,diagnosis not possible. & 1 \\
Material & 2.Sufficient for cytodiagnosis. & 2 \\
\hline Cell morphology, cellular & 3.Abundant, diagnosis simple. & 0 \\
degeneration and trauma & 2.Marked cellular degeneration,diagnosis not possible. & 1 \\
& 3.Minimal cellular degeneration, diagnosis easy. & 2 \\
\hline Distribution of cells & 1.Totally in the periphery or sparsely distributed. & 0 \\
& 2.Combination. & 1 \\
\hline
\end{tabular}


Pleural Fluid: Total No of Cases-39

Table 4: Comparison of cell yield in pleural fluid samples

\begin{tabular}{|l|c|c|c|}
\hline Method & Score 0 & Score 1 & Score 2 \\
\hline Centrifuge & $2(5 \%)$ & $29(74 \%)$ & $08(21 \%)$ \\
\hline Cytospin & $2(5 \%)$ & $16(41 \%)$ & $21(54 \%)$ \\
\hline
\end{tabular}

CF showed a cellularity score of 0 in 2 cases, 1 in 29 cases and 2 in 08 cases. CS showed a cellularity score of 0 in 2 cases, 1 in 16 cases, 2 in 21 cases. The maximum cellularity score 2 was seen in the CS smears of 21 cases whereas it was observed in 8 cases of $\mathrm{CF}$.

Table 5: Comparison of Cell Morphology in pleural fluid samples

\begin{tabular}{|l|c|c|c|}
\hline Method & Score 0 & Score 1 & Score 2 \\
\hline Centrifuge & $1(2 \%)$ & $25(65 \%)$ & $13(33 \%)$ \\
\hline Cytospin & $1(2 \%)$ & $8(20 \%)$ & $30(78 \%)$ \\
\hline
\end{tabular}

Cell morphology in CF showed score 0 in 1 case, score 1 in 25 cases and score 2 in 13cases. Cell morphology in the CS showed score 0 in 1 case, score 1 in 8 cases and score 2 in 30 cases.

Table 6: Comparison of Cell Distribution in pleural fluid samples

\begin{tabular}{|l|c|c|c|}
\hline Method & Score 0 & Score 1 & Score 2 \\
\hline Centrifuge & $6(15 \%)$ & $24(61 \%)$ & $9(24 \%)$ \\
\hline Cytospin & $4(! 0 \%)$ & $10(25 \%)$ & $25(65 \%)$ \\
\hline
\end{tabular}

Cell distribution in CF showed score 0 in 6 cases, score 1 in 24 cases and score 2 in 9 cases. Cell distribution in CS showed score 0 in 4 cases, score 1 in 10 cases and score 2 in 25 cases.

Table 7: Comparison of Background in pleural fluid samples

\begin{tabular}{|l|c|c|c|}
\hline Method & Score 0 & Score 1 & Score 2 \\
\hline Centrifuge & $5(12 \%)$ & $22(56 \%)$ & $12(32 \%)$ \\
\hline Cytospin & $3(7 \%)$ & $22(56 \%)$ & $14(37 \%)$ \\
\hline
\end{tabular}

With regard to background, CF showed score 0 in 5 cases, score 1 in 22 cases and score 2 in 12 cases and CS showed score 0 in 3 cases, score 1 in 22 cases and score 2 in 14 cases

\section{Statistical Analysis of All the Morphological Parameters of Pleural Fluid}

According to Chi-Square test, the results are analysed and tabulated as follows.
Table 8: Statistical Analysis of all the Morphological Parameters of Pleural Fluid

\begin{tabular}{|l|c|c|}
\hline Parameters & Chi-square & P value \\
\hline Cellularity & 9.589 & 0.0083 \\
\hline Cell morphology & 15.479 & 0.0004 \\
\hline Cell distribution & 13.694 & 0.0011 \\
\hline Background & 0.6538 & 0.7211 \\
\hline
\end{tabular}

\section{Peritoneal Fluid: Total No of Cases-48}

Table 9: Comparison of cellularity in peritoneal fluid samples

\begin{tabular}{|l|c|c|c|}
\hline Method & Score 0 & Score 1 & Score 2 \\
\hline Centrifuge & $5(10 \%)$ & $38(80 \%)$ & $5(10 \%)$ \\
\hline Cytospin & $4(8 \%)$ & $26(55 \%)$ & $18(37 \%)$ \\
\hline
\end{tabular}

CF showed a cellularity score of 0 in 5 cases, 1 in 38 case and 2 in 5 cases. CS showed a cellularity score of 0 in 4 cases, 1 in 26 cases, 2 in 18 cases .The maximum cellularity score 2 was seen in the CS smears of 17 cases whereas it was observed in 7 cases of CF.

Table 10: Comparison of Cell Morphology in peritoneal fluid samples

\begin{tabular}{|l|c|c|c|}
\hline Method & Score 0 & Score 1 & Score 2 \\
\hline Centrifuge & $5(10 \%)$ & $38(79 \%)$ & $5(10 \%)$ \\
\hline Cytospin & $3(6 \%)$ & $5(10 \%)$ & $40(84 \%)$ \\
\hline
\end{tabular}

Cell morphology in CF showed score 0 in 5 case, score 1 in 38 cases and score 2 in 5cases. Cell morphology in the CS showed score 0 in 3 case, score 1 in 5 cases and score 2 in 40 cases.

Table 11: Comparison of Cell distribution in peritoneal fluid samples

\begin{tabular}{|l|c|c|c|}
\hline Method & Score 0 & Score 1 & Score 2 \\
\hline Centrifuge & $9(18 \%)$ & $35(72 \%)$ & $4(8 \%)$ \\
\hline Cytospin & $4(8 \%)$ & $13(27 \%)$ & $31(64 \%)$ \\
\hline
\end{tabular}

Cell distribution in CF showed score 0 in 9 cases, score 1 in 35 cases and score 2 in 4 cases. Cell distribution in CS showed score 0 in 4 cases, score 1 in 13 cases and score 2 in 31 cases.

Table 12: Comparison of background in peritoneal fluid samples

\begin{tabular}{|l|c|c|c|}
\hline Method & Score 0 & Score 1 & Score 2 \\
\hline Centrifuge & $4(8 \%)$ & $36(75 \%)$ & $8(4 \%)$ \\
\hline Cytospin & $3(6 \%)$ & $35(72 \%)$ & $10(20 \%)$ \\
\hline
\end{tabular}

With regard to background, CF showed score 0 in 4 cases score 1 in 36 cases and score 2 in 8 cases 
and CS showed score 0 in 6 cases, score 1 in 35 cases and score 2 in 10 cases

\section{Statistical Analysis of all the Morphological parameters of Peritoneal Fluid}

According to Chi-Square test, the results are analysed and tabulated as follows.

Table 13: Statistical Analysis of all the Morphological Parameters of Peritoneal Fluid

\begin{tabular}{|l|c|c|}
\hline Parameters & Chi-square & P value \\
\hline Cellularity & 53.04 & $<0.0001$ \\
\hline Cell morphology & 9.709 & 0.0078 \\
\hline Cell distribution & 32.835 & $<0.0001$ \\
\hline Background & 0.3792 & 0.8273 \\
\hline
\end{tabular}

\section{CSF: Total No of Cases-13}

Table 14: Comparison of cell yield in CSF samples

\begin{tabular}{|l|c|c|c|}
\hline Method & Score 0 & Score 1 & Score 2 \\
\hline Centrifuge & $1(7 \%)$ & $10(78 \%)$ & $2(15 \%)$ \\
\hline Cytospin & $1(7 \%)$ & $4(30 \%)$ & $8(63 \%)$ \\
\hline
\end{tabular}

CF showed a cellularity score of 0 in 1 cases, 1 in 10 cases and 2 in 2 cases. CS showed a cellularity score of 0 in 1 cases, 1 in 4 cases, 2 in 8 cases .The maximum cellularity score 2 was seen in the CS smears of 8 cases whereas it was observed in 2 cases of $\mathrm{CF}$.

Table 15: Comparison of Cell Morphology in CSF samples

\begin{tabular}{|l|c|c|c|}
\hline Method & Score 0 & Score 1 & Score 2 \\
\hline Centrifuge & $1(7 \%)$ & $8(63 \%)$ & $4(30 \%)$ \\
\hline Cytospin & $1(7 \%)$ & $2(15 \%)$ & $10(78 \%)$ \\
\hline
\end{tabular}

Cell morphology in CF showed score 0 in 1 case, score 1 in 8 cases and score 2 in 4 cases. Cell morphology in the CSshowed score 0 in 1 case, score 1 in 2 cases and score 2 in 10 cases.

Table 16: Comparison of Cell Distribution in CSF samples

\begin{tabular}{|l|l|l|l|}
\hline Method & Score 0 & Score 1 & Score 2 \\
\hline Centrifuge & $2(15 \%)$ & $8(64 \%)$ & $3(23 \%)$ \\
\hline Cytospin & $2(15 \%)$ & $2(15 \%)$ & $9(70 \%)$ \\
\hline
\end{tabular}

Cell distribution in CF showed score 0 in 2 cases, score 1 in 8 cases and score 2 in 3 cases. Cell distribution in CS showed score 0 in 2 cases, score 1 in 2 cases and score 2 in 9 cases.
Table 17: Comparison of Background in CSF samples

\begin{tabular}{|l|c|c|c|}
\hline Method & Score 0 & Score 1 & Score 2 \\
\hline Centrifuge & $2(15 \%)$ & $9(70 \%)$ & $2(15 \%)$ \\
\hline Cytospin & $1(7 \%)$ & $9(70 \%)$ & $3(23 \%)$ \\
\hline
\end{tabular}

With regard to background, CF showed score 0 in 2 cases, score 1 in 9 cases and score 2 in 2 cases and CS showed score 0 in 1 cases, score 1 in 9 cases and score 2 in 23 cases

\section{Statistical Analysis of all the Morphological parameters of CSF}

According to Chi-Square test, the results are analysed and tabulated as follows.

Table 18: Statistical Analysis of all the Morphological Parameters of CSF

\begin{tabular}{|l|c|l|}
\hline Parameters & Chi-square & P value \\
\hline Cellularity & 6.17 & 0.0457 \\
\hline Cell morphology & 6.171 & 0.0457 \\
\hline Cell distribution & 6.600 & 0.0369 \\
\hline Background & 0.533 & 0.7659 \\
\hline
\end{tabular}

\section{Result}

\section{Inference in Pleural Fluid}

Cell yield is better in cytospin than conventional. The results showed that there is statistically significant difference between the two methods. $(\mathrm{P}$ value $=0.0083)$

Cell morphology is better preserved in smears obtained by cytospin than conventional. These results show statistically significant difference between the methods. $\mathrm{P}$ value $=0.0004$ )

Cytospin demonstrated more uniform distribution of cells than conventional, which was statistically significant. $(\mathrm{P}$ value $=0.0011)$

Background: These results are not statistically significant $(\mathrm{P}$ value $=0.7211)$. Hence background was not comparable between the two methods.

\section{Inference in Peritoneal Fluid}

Cell yield is better in cytospin than centrifuge. The results showed that there is statistically significant difference between the two methods. $(\mathrm{P}$ value $<0.0001)$

Cell morphology is better preserved in smears obtained by cytospin than centrifuge. These 


\section{JMSCR Vol||08||Issue||01||Page 147-153||January}

results show statistically significant difference between the methods. ( $\mathrm{P}$ value $<0.0078$ )

Cytospin demonstrated more uniform distribution of cells than centrifuge, which was statistically significant. (P value $<0.0001$ )

Background: These results are not statistically significant ( $\mathrm{P}$ value=0.8273). Hence background was not comparable between the two methods.

\section{Inference in CSF}

Cell yield is better in CS than CF. The results showed that there is statistically significant difference between the two methods. (P value $=0.0457$ )

Cell morphology is better preserved in smears obtained by CS than CF. These results show statistically significant difference between the methods. $(\mathrm{P}$ value $=0.0457)$

Cytospin demonstrated more uniform distribution of cells than centrifuge, which was statistically significant. ( $\mathrm{P}$ value $=0.0369$ )

Background: These results are not statistically significant ( $\mathrm{P}$ value=0.7659). Hence background was not comparable between the two methods.

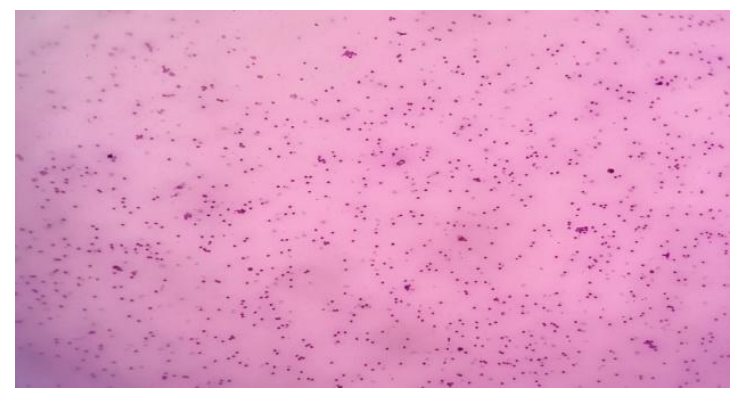

Fig 1: Unenven distribution and cell yield in centrifuge smear (Leishman Giemsa;10X)

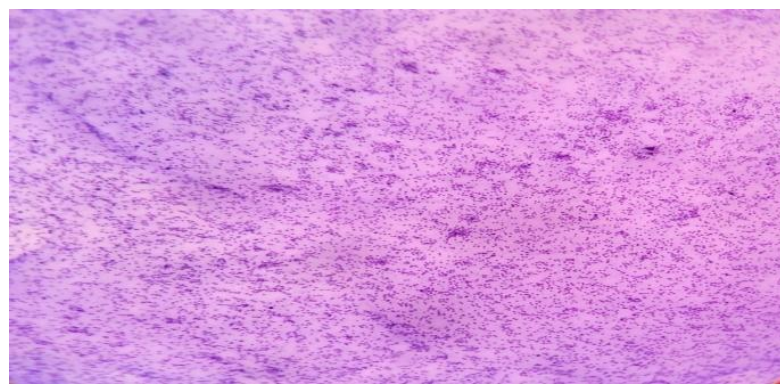

Fig 2: Even distribution and cell yield in cytospin smea $\mathrm{r}(10 \mathrm{X})$

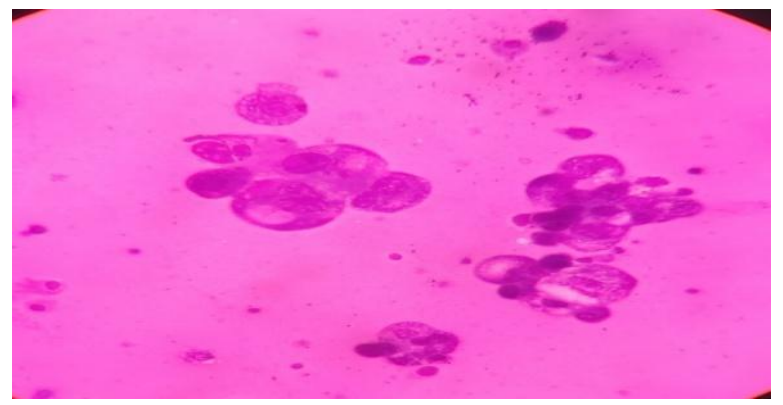

Fig 3: Moderate cellular degeneration in centrifuge smear (Leishman, Giemsa 40X)

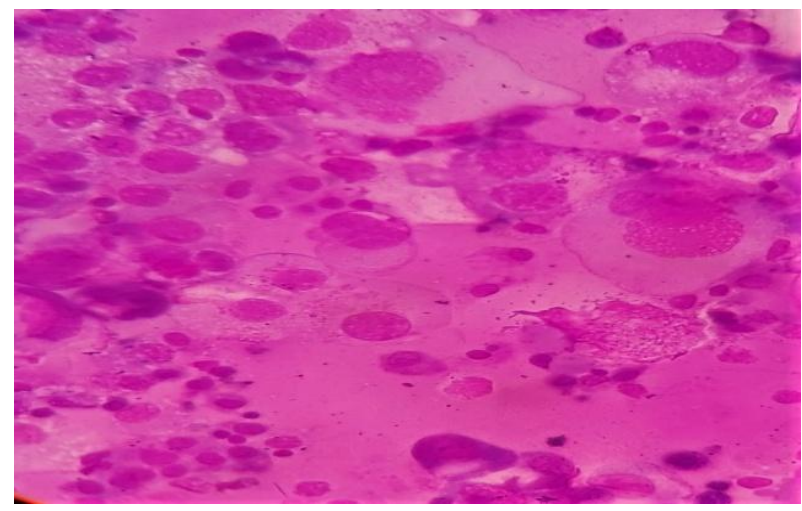

Fig 4: Minimal cellular degeneration in cytospin smear (Leishman, Giemsa 40X)

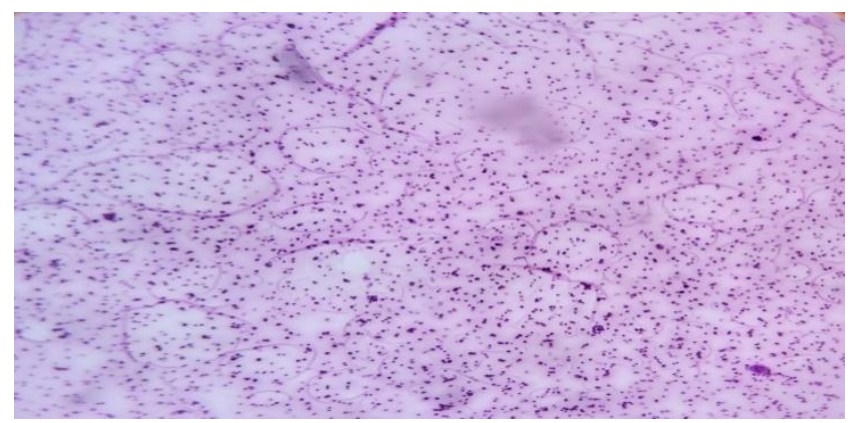

Fig 5: Background proteinaceous material moderate, diagnosis possible (Leishman, Giemsa 10X)

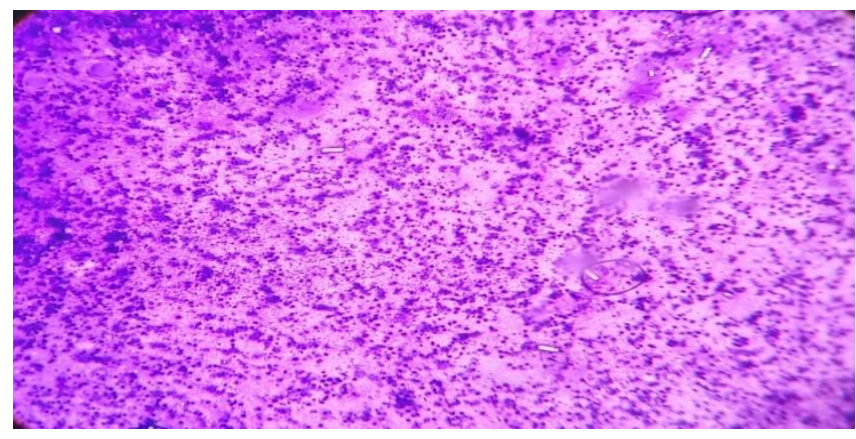

Fig 6: Background proteinaceous material moderate, diagnosis possible (Leishman, Giemsa 40X) 


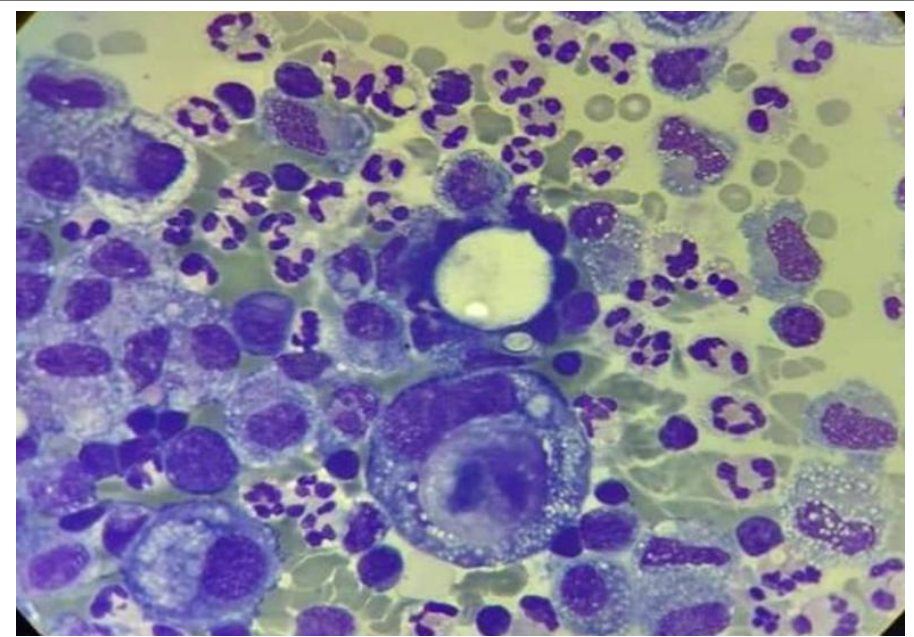

Fig 7: Metastatic adenocarcinoma (Leishman, Giemsa 40X)

\section{Discussion}

In our laboratory, we routinely use conventional centrifugation technique for preparing smears from fluid samples. But we are posed with muchdifficulties in interpreting these fluids because of the decreased cellularity and poor preservation of morphology of the cells. Hence in our laboratory we conducted a study comparing the conventional technique with the Cytospin technique. The smears were compared on the morphological parameters such as cellularity, cytomorphology, cell distribution and background.

\section{Cell Yield}

The number and type of cells give information about the target tissue. The cell yield is influenced by lesional and lesional factors particularly type of sampling method employed.

In our study, CS showed better cellularity than CF in all the 3 types of fluids such as pleural, peritoneal and CSF. Better cellularity helps in early diagnosis and it also eliminates the need for repeat tap.

\section{Cell Morphology}

In our study, one important finding was good preservation of cytomorphologic details in CS as compared to $\mathrm{CF}$ in all 3 types of fluids. Cytomorphological preservation plays an important role for the identification of the diagnostic cells. It is used to differentiate benign from malignant cells ${ }^{8}$.

\section{Cell Distribution}

Uniform cell distribution provides a better visual image of the disease process. It will help in easy and rapid screening and decreases the number of unsatisfactory specimens. In our study, cytospin demonstrated more uniform distribution of cells than conventional, which was statistically significant $(\mathrm{p}<0.05)$.

\section{Background}

In our study, even though clean background were seen in more number number of cases in CS than $\mathrm{CF}$ in all 3 types of fluids, they were not comparable because the results were not statistically significant.

\section{Others}

In our study, out of the 39 pleural fluid samples, one case was diagnosed as malignancy by both $\mathrm{CF}$ and CS. Among the 48 peritoneal fluids, 4 were diagnosed as malignancy by $\mathrm{CF}$ and 1 by CS. Our study included 13 samples of CSF and malignant cells were seen in no sample by both CF and CS.

\section{Summary}

This study was conducted to compare the performance of CS and CF in body cavity fluids like pleural, peritoneal fluids and CSF. Total 100 fluid samples were subjected to cytologic examination, out of which 39 were pleural fluids, 48peritoneal fluids and $13 \mathrm{CSF}$ samples. Majority of the samples were non-neoplastic (95 out of 100). Among 95 non-neoplastic samples, 38 (40\%) were pleural fluid,44(46.3\%) were peritoneal and 13 were $\operatorname{CSF}(13.6 \%)$.Out of the 100 fluid samples, 5 were malignant effusions. Among 5 neoplastic effusions, 1 (20\%)was pleural, 4 were peritoneal(80\%).Four morphological parameters were compared between CS and CF like cell yield, cell morphology, cell distribution and clean background. Cell Yield: CS showed better cell yield as compared to CSF in pleural, peritoneal fluids and CSF. The results were statistically significant $(\mathrm{p}<0.05)$. Cell Morphology: Cell morphology was better preserved by CS than $\mathrm{CF}$ in pleural, peritoneal fluids and CSF. This was 
proved significant by $\mathrm{p}$ value less than 0.05 . Cell Distribution: CS showed more uniform cell distribution as compared to $\mathrm{CF}$ in pleural, peritoneal fluids and CSF. These results showed a statistically significant difference between the two methods. $\quad(p<0.05)$ Background: The results obtained from both methods were not statistically significant. $\quad(p>0.05)$. Hence CS was not comparable to $\mathrm{CF}$ in terms of background. This was true forpleural, peritoneal fluids and CSF.

\section{Conclusion}

Cytospin was found superior to conventional centrifuge smears in terms of cell yield, preservation of cell morphology and uniformity of cell distribution. Cytospin helped in better diagnosing malignant effusions than conventional smears. Hence, cytospin can be preferred to conventional smears for cytologic examination of body cavity fluids. With regard to typing the characteristics of malignant effusions, more samples have to be analysed and a separate study is required.

\section{References}

1. Koss LG and Melamed MR (Eds). Koss' Diagnostic cytology and its histopathologic bases.5th edition, Philadelphia: JB Lippincott Company; 2006.pp11(a); 12(b); 950

2. Ehya H.Effusion cytology. Clinics in laboratory medicine.; 11(2): 443-67

3. Nathan NA, Narayan E, Smith MM, Horn MJ. Cell block cytology-Improved preparation and its efficacy in diagnostic cytology. Am J Clin Pathol 2005;114: 599606

4. Kushwaha R, Shashikala P, Hiremath S, Basavaraj HG. Cells in pleural fluid and their value in differential diagnosis. $\mathrm{J}$ Cytol 2008;25:138-43

5. Yamamoto S, Akasu T, Fujita S, Moriya Y. Long term Prognostic value of conventional peritoneal Cytology after curative Resection for colorectal
Carcinoma. Japanese Journal of Clinical Oncology 2005; 33: 33-37.

6. Jha R, Shrestha HG, Sayami G, Pradhan SB. Study ofeffusion cytology in patients with simultaneous malignancy and ascites. Kathmandu University Medical Journal 2006; 4

7. Archana Joshi, Nidhi Mahajan, Karmarkar. Diagnostic utilityMof various techniques used in body fluid cytology. IOSRJournal of Dental and Medical Sciences 2014;13(1):13-18

8. Baig MA, Fathallah L, Feng J, Husain M, Grignon DG, Al Abbadi MA. Fast drying of Fine Needle Aspiration slides113using a hand held fan: Impact on turnaround time and staining quality. CytoJournal 2006; $3: 12$. 